\title{
The medical profession must urgently act on caste-based discrimination and harassment in their midst
}

\author{
KIRAN KUMBHAR
}

\begin{abstract}
Abuse and bullying during medical residency are common experiences of most doctors in India, but do not seem to have invited any major corrective action from the leaders of the medical profession. This kind of abuse is also on many occasions fuelled by prevalent misconceptions around caste hierarchies and the supposed nondeserving nature of students who enter the profession using reservations. The professional leadership has similarly turned a blind eye to the dominance of such damaging ideas and myths on college and hospital campuses, which in unfortunate instances have led to agonising mental torture and deaths by suicide of harassed students. The medical profession needs to collectively act on workplace abuse as well as casteist harassment before it is too late.
\end{abstract}

Keywords: Adivasi, caste, Dalit, medical education, reservations

\section{Background}

Barua and Verma, in a thoughtful commentary published in this journal, discuss many crucial facets of workplace bullying and the culture of abuse in medical colleges and teaching hospitals in India (1). For decades medical students in the country have had to undergo an intense rite of passage commonly referred to as "ragging." In the late 1970s a high court judge, presiding over a case of ragging in a medical college, noted that what ragging means "has passed so much into popular parlance that we feel that any elucidation of the term would be unnecessary." (2). When graduates join hospitals as resident doctors, they face yet another set of ritualised abusive practices, which Barua and Verma describe as "teaching by humiliation and mistreatment." In other words, abuse of juniors is strongly institutionalised in the country's medical training culture. What is of urgent importance now, in the wake of the troublingly condoning official response to the

Authors: Kiran Kumbhar (kumbhar@g.harvard.edu), Doctoral Student in the History of Science, Harvard University, Cambridge, MA 02138, USA.

To cite: Kumbhar K. The medical profession must urgently act on castebased discrimination and harassment in their midst. Indian J Med Ethics. 2021 Jan-Mar; 6(1) NS: 49-51. 2020. DOI:10.20529/IJME.2020.121.

Published online first on November 23, 2020

Manuscript Editor: Rakhi Ghoshal

(c) Indian Journal of Medical Ethics 2020 death by suicide of Dr Payal Tadvi, is to understand how casteist discrimination (here I also mean discrimination against Adivasi communities, officially known as "Scheduled Tribes") intersects with the broader culture of abuse in medical training (3).

Decades-long affirmative action has ensured that every year many students and doctors from historically marginalised communities enter the country's medical institutions and assimilate into, as well as absorb, the prevalent cultures there including the culture of abuse. Today, students and doctors who perpetrate ragging and workplace bullying transcend caste and other social identities. Barua and Verma also say that regardless of caste, "all trainee doctors get reprimanded for substandard work." Hence, the phenomenon of specifically casteist bullying which in the case of Dr Tadvi led to her tragic death needs to be evaluated against this general background of abusive workplace culture in medical colleges and hospitals.

\section{Castebased beliefs and myths among medicos}

An attempt at such an evaluation logically leads to some important questions - questions to which we do not have complete answers yet, but are open for researchers to explore. While senior doctors and professors are known to yell at almost everyone under their supervision (which in itself is highly problematic behaviour), do they scold some doctors more frequently than others? Do their inherent biases overpower their duty of fairness, with only some juniors bearing a disproportionately large amount of their berating? Are there instances where a senior might viciously scream at a junior for a supposed error but only lightly rebuke another for the same error, and does this differential attitude stem from casteist affiliation and prejudice? Do prevalent myths about Dalit and Adivasi doctors not being "talented" and "deserving" enough influence how seniors evaluate their work, including successes and errors? Suicide attempts and deaths by suicide are, unfortunately, not an uncommon occurrence on medical and teaching hospital campuses. What is the proportion of casteism-abetted suicides in total suicides, and how frequent are these?

Students from historically marginalised castes and tribes have for decades been drawing attention to the abusive behaviour and casteist harassment perpetrated by their privileged caste seniors and colleagues (4). In instances of deaths by suicide and suicide attempts, there is invariably a history of prolonged 
insults and torture. So while not all the abuse in teaching hospitals and medical colleges is directly related to caste, casteism does fuel much abuse, and Dalits and Adivasis end up bearing the most adverse consequences. This disparity is seen even in other professional institutions, not to mention the society as a whole. Beginning in 1992 with the death by suicide of Chuni Kotal, a student from the Lodha tribe in Bengal - an incident which many senior doctors today might remember - instances of harassment of Dalit and Adivasi scholars have been unsettlingly regular (5). The colleagues of one such Dalit scholar, Senthilkumar, wrote in 2008:"How many more dropouts, humiliations and deaths will we need before recognising that institutions must be held accountable and the guilty punished?" (6)

Two recent studies by anthropologists provide a visceral picture of how casteism, and caste-based myths around intelligence and merit, are dominant in Indian institutions. One of these, by Harvard university professor Ajantha Subramanian, deals with IIT Madras, in which we hear a former student saying:"SC students... were definitely treated as intellectually inferior... There was a pretty clear sense that they shouldn't be there but managed to get in only because of the quota. Some professors would also treat them very badly" (7) In the other study, which is an important ethnography of MBBS students at AlIMS by Dr. Anna Ruddock, we learn that Dalit and Adivasi students are often labeled as "coasters" - with the flawed, offensive assumption that reservations somehow make the process of admission "easy" for them (8).

Scholars have extensively commented on the myth of merit and on how the popular idea of merit as applied to admissions through competitive and supposedly objective tests, does not lead to a meaningful analysis of public good (9). Of direct concern to this essay is the fact that these ideas nevertheless are highly prevalent and end up stripping many Dalit and Adivasi doctors of their basic right to be treated as a human being and as an equal colleague at the workplace. The inhumanness of these concepts of merit and of the received ideas about reservations was what seems to have severely affected Dr Tadvi at the BYL Nair Hospital. We know through the police charge-sheet that at least three staff members had witnessed her seniors bully her and use casteist slurs, including saying "People like you can only be clerks" (10).

\section{Acknowledging the casteism in our midst}

Social scientists have shown that collectively, our nation has performed very poorly in terms of treating fellow humans as equals. Among the many reasons for that is the centurieslong persistence of caste-based ways of thinking (11). Students and doctors from privileged castes live in this unequal cultural environment and imbibe the dominant ideas and justifications of inequality - even if these are incorrect which then, unsurprisingly, spring up during conversations in college canteens, hospital wards, operation theatres etc. Again, as scholars have consistently shown, the inequalities and abuses around us are frequently dealt with through denial and indifference (12). Thus, while offensive claims about the abilities and intelligence of Dalit and Adivasi students and doctors continue unabated within the medical community, prominent medical bodies and associations are reluctant to acknowledge these facts. For example, the authorities at the Maharashtra Medical Council have deemed it fit to not punish the three individuals who Dr Tadvi specifically mentioned in her final letter as her torturers (their inhumane and unprofessional behaviour was also corroborated by other evidence gathered by the hospital's anti-ragging committee) (13). At the same time, the Indian Medical Association (IMA) seems to be denying and ignoring the overwhelming evidence of casteism on campuses and strangely maintaining that "there is no caste discrimination in Indian medical field" (14).

The leaders of the profession in India must know that such denial only leads to explosive situations sooner or later. Doctors already have experienced that, with respect to medical negligence and malpractice. For a long time these serious issues were ignored by professional bodies, often with the bland justification that erring doctors were only a "few black sheep." But over the past decade, as we are aware, there has been an explosion of the already simmering anti-doctor sentiment in the public, much of it fueled by anger against the medical corruption and malpractice which the profession had ignored for decades. Casteism in medicine might end up on that path if not acknowledged and acted upon urgently.

The IMA and other professional bodies can take a leaf out of the British Medical Association's (BMA) attitudes towards racism in medicine in the UK. In recent years the BMA has openly discussed the issue and strongly advocated for equal and respectful treatment of Black, Asian, and minority ethnic trainee doctors in the country. They have also conducted surveys and studies on minority doctors' experiences of discrimination and racism (15). India will need several such studies, considering the multiple forms of discrimination and the geographic variation we have in cultures. Besides, it would be pertinent to study the administrative and decision-making leadership of our prominent medical bodies and analyse the under-representation of minority communities there. A cursory look at the top office-bearers in IMA, MCI (Medical Council of India, now National Medical Commission) and similar bodies in recent years makes it clear that minority representation is negligible in the profession's official leadership roles. Not surprisingly, the actions of these organisations have shown neither a clear understanding of the ground reality of discrimination, nor genuine empathy with the lived experience of the humiliation and the anger that accompanies it.

On the more immediate timescale, people at the helm of medical colleges and hospitals must start taking seriously all complaints about harassment. They should also seek 
assistance from suitable experts to create plans of action to sensitise students and doctors regarding casteism and other forms of discrimination, and to institutionalise redressal mechanisms and mental well-being avenues for those subjected to bullying and harassment. The Indian medical profession today is rightly worried about the regular incidents of abuse and violence against doctors at the hands of the public. But it is disappointing that the regular abuse and violence against doctors at the hands of other doctors (both caste-based and otherwise) has been normalised as an almost integral part of medical training. There are few organised voices, like those of the Medico Friend Circle and the Jan Swasthya Abhiyan, which consistently attempt to highlight these issues and deliberate potential solutions. It is high time the rest of the profession joined in with all their might.

\section{References}

1. Barua MP, Verma A. Workplace bullying in healthcare facilities: Role of caste and reservation. Indian J Med Ethics. 2021 Jan-Mar ;6(1) NS:44-46. DOI: 10.20529/IJME.2020.107.

2. RC Thampan and Ors vs The Principal, Medical College, Calicut, on 6 September 1978, AIR 1979 Ker 171 [cited 2020 Nov 5]. Available from: https://indiankanoon.org/doc/1851109/

3. Shantha S. Payal Tadvi suicide case: Supreme Court allows accused doctors to pursue higher education. Wire.in. 2020 Oct 8 [cited 2020 Nov 5]. Available from: https://thewire.in/law/payal-tadvi-suicide-casesupreme-court-allows-accused-doctors-to-pursue-higher-education

4. Karthikeyan D. Suicide by Dalit students in 4 years. Hindu.com. 2011 Sep 5 [cited 2020 Nov 5]. Available from: https://www.thehindu.com/ news/cities/Madurai/suicide-by-dalit-students-in-4-years/ article2425965.ece
5. Devi M. Story of Chuni Kotal. Econ Pol Wkly. 1992 Aug 29; 27(35), 18367.

6. Senthilkumar Solidarity Committee. Caste, Higher Education and Senthil's "Suicide." Econ Pol Wkly. 2008 Aug 16; 43(33): 10-12.

7. Subramanian A. The caste of merit: Engineering education in India. Harvard: Harvard University Press; 2019

8. Ruddock AL. Special medicine: Producing doctors at the All India Institute of Medical Sciences (AlIMS). PhD dissertation, University of London, King's College; 2017.

9. Lenfield SL. Michael Sandel makes the case against meritocracy. Harvard Magazine. 2020 Sep [cited 2020 Nov 6]. Available from: https:// harvardmagazine.com/2020/09/montage-michael-sandel-againstmeritocracy

10. Shantha S. Payal Tadvi case: Chargesheet reveals months of humiliation, discrimination. Wire.in. 2019 Jul 25[cited 2020 Nov 6]. Available from:https://thewire.in/rights/dr-payal-tadvi-suicidechargesheet

11. Ambedkar BR. Why BR Ambedkar's three warnings in his last speech to the Constituent Assembly resonate even today. Scroll.in. 2016 Jan 26[cited 2020 Nov 6], Available from: https://scroll.in/article/802495/ why-br-ambedkars-three-warnings-in-his-last-speech-to-theconstituent-assembly-resonate-even-today

12. Mehta PB. Why we don't talk about inequality - and how to start again. Caravan. 2012 Sep 30[cited 2020 Nov 6]. Available from: https:// caravanmagazine.in/caste/breaking-silence

13. Modak S. Payal Tadvi suicide case: MMC restores medical licences of two accused doctors, family writes to minister. Indian Express. $2020 \mathrm{Jul}$ 18[cited 2020 Nov 6]. Available from: https://indianexpress.com/ article/ india/payal-tadvi-suicide-case-mmc-revokes-medical-licencesof-two- accused-doctors-family-writes-to-minister-6511231/

14. Bhuyan, A. Even after Payal Tadvi's death, doctors' body unconvinced of caste discrimination. Wire.in. 2019 May 28[cited 2020 Nov 6] Available from: https://thewire.in/caste/payal-tadvi-doctor-castediscrimination

15. Adebowale $\mathrm{V}$, Rao M. Racism in medicine: Why equality matters to everyone. BMJ. 2020 Feb 12[cited 2020 Nov 6]; 368: m530. Available from: https://doi.org/10.1136/bmj.m530

\title{
Workplace bullying in medical institutions: Response to Karpagam
}

\author{
ANITA VERMA, MRINAL PRAKASH BARUA
}

\section{Keywords: workplace bullying, caste, suicide, discrimination}

Workplace bullying is the exhibition of repeated, hostile behaviours toward one or more individuals that are unwanted by the target(s) and cause humiliation, distress, or harm to that individual or group. (1)

In India, workplace bullying is generally actionable under the law only if bullying behaviour is directed against sections acknowledged as being vulnerable (also known as

Author: Anita Verma (anitav.psyc@aiimsrishikesh.edu.in), Senior Resident, Department of Psychiatry, All India Institute of Medical Sciences, Rishikesh, Uttarakhand INDIA; Mrinal Prakash Barua (corresponding author mrinalbarua@gmail.com), Additional Professor, Department of Anatomy, All India Institute of Medical Sciences, Rishikesh, Uttarakhand, INDIA.

To cite: Verma A, Barua MP. Workplace bullying in medical institutions: Response to Karpagam. Indian J Med Ethics. 2021 Jan-Mar; 6(1) NS: 51-52. DOI:10.20529/IJME.2021.008.

(c) Indian Journal of Medical Ethics 2020 harassment) or if it amounts to criminal wrong such as assault or battery (or sometimes "ragging"). This is bizarre considering the fact that workplace bullying is unconstitutional in the context of Articles 21, 42, 43 of the Constitution of India. We therefore assume that bullying, irrespective of the caste factor, is a serious problem. In cases of suicide, it is tricky to label bullying as abetment, even for the courts, because the perceptions of the victim are also important. The latter, unfortunately, are inaccessible hence one has to work it out retrospectively, using circumstantial evidence.

We are somewhat puzzled by Dr Karpagam's populist stance on our article. In our article (2), we had shared an observation that a culture of workplace bullying is embedded in teaching hospitals in India, and commented on how social attributes like caste could play a role. As the issue central to the article (3) is a doctor's death by suicide, perhaps as a result of bullying by her seniors, we have laid more emphasis on bullying than on its antecedents. We acknowledge that factors like caste may 